Research Article

\title{
Neurodevelopmental comorbidity profile in specific learning disorders
}

\author{
Alpana Somale, Santosh V. Kondekar*, Surbhi Rathi, Nisha Iyer
}

Department of Pediatrics, T N Medical College, Mumbai-400008, INDIA

Received: 10 March 2016

Accepted: 18 March 2016

*Correspondence:

Dr. Santosh V. Kondekar,

E-mail: drkondekar@gmail.com

Copyright: () the author(s), publisher and licensee Medip Academy. This is an open-access article distributed under the terms of the Creative Commons Attribution Non-Commercial License, which permits unrestricted non-commercial use, distribution, and reproduction in any medium, provided the original work is properly cited.

\begin{abstract}
Background: Specific learning disorders (SLD) are the common reasons for referral of an otherwise healthy child from a main stream school. Although children do have difficulties even in early learning years in pre-primary and primary school; a significant number of preadolescent children from mainstream school do present with such disabilities. Primary objective was to study the differential distribution of various comorbidities across SLD spectrum. Secondary objective was to check for prevalence of abnormal neurological examination findings including soft signs.

Methods: After approval of institutional ethics committee, 100 consecutive case records of children presenting to the center were studied. Diagnosis was confirmed as per DSM V criteria. The clinical, psychological and neurological information was derived from notes of pediatrician, after SLD certification. Details about history, ADHD and comorbidities if any were recorded from parents where documented information was not sufficient. The prevalence of comorbidities was expressed as a percentage of total cases studied.

Results: ADD of combined type was the commonest comorbidity seen in 53\% cases. Other occasional comorbidities noted were epilepsy, autism, cerebral palsy, history of meningitis and febrile seizures. Speech and visuospatial skills were affected $10 \%$ and $41 \%$ in children with SLD and all of these had ADD. Soft neurological signs like astereognosis, graphesthesia, dysdiadochokinesia, dysmetria were seen in more than $20 \%$ cases. Abnormal antenatal and perinatal history was more common in ADHD with SLD.

Conclusions: SLD children from mainstream schools usually have ADHD as commonest comorbidity. Often they should be looked for various neurological comorbidites like autism, epilepsy, cerebral palsy. Soft signs and motor delay need not be overlooked in view of comprehensive management. A large multicentric study is needed to look for soft neurological signs; neuroimaging may be needed in SLD to understand the disorders in cognitive spectrum.
\end{abstract}

Keywords: Dyslexia, Specific learning disorder, Comorbidity, ADHD

\section{INTRODUCTION}

Awareness of specific learning disorder (SLD) in India existed two decades ago. Kulkarni $\mathrm{M}$ et al described approach to learning disabilities and also stated that dyslexia and its comorbidities affect true potential and ability of an individual. ${ }^{1}$ Despite all facilities and capabilities; few children in mainstream schools do have issues related to reading, writing, basic arithmetic skills appropriate for the age. These children do present at times in early learning years; or they present at age when complex learning issues are involved.
Previously known as dyslexia or learning disability; now as per DSM V classification it is labeled as Specific Learning Disorder (SLD). ${ }^{2}$ In 2013, DSM-5 defined a Specific Learning Disorders (SLD) as "difficulties in learning and using academic skills". Alves LM had noted that school children took longer time to conclude tasks when they had SLD or ADHD. ${ }^{3}$ Governments have introduced special concessions or assistance to the certified children by making special legal provisions. These learning difficulties are likely to be innate and due to central nervous system dysfunction. They are not better accounted for by intellectual disabilities, 
uncorrected visual or auditory acuity, other mental or neurological disorders, psychosocial adversity, lack of proficiency in the language of academic instruction, or inadequate educational instruction. ${ }^{2}$

The following describes the updated 2013 DSM-5 diagnostic subtypes of specific learning disorder: ${ }^{4}$

1) Specific learning disorder with impairment in reading includes possible deficits in: word reading accuracy, Reading rate or fluency, reading comprehension. 2) Specific learning disorder with impairment in written expression includes possible deficits in: spelling accuracy, grammar and punctuation accuracy, clarity or organization of written expression. 3) Specific learning disorder with impairment in mathematics includes possible deficits in: number sense, memorization of arithmetic facts, accurate or fluent calculation, accurate math reasoning.

Changed spectrum of SLD as per new criteria, does create challenges and generate need for revisions in comparative research, clinical evaluations and implementations of Individuals with disabilities education act (IDEA) in school settings. ${ }^{5}$

Schulte-körne $\mathrm{G}$ described prevalence of these disorders as $5-15 \%{ }^{4}$ Sahoo et al quoted prevalence as $2-10 \%$, in school children with $30 \%$ these having neuropsychiatric issues like ADHD, behavioural problems,anxiety, depression that may go unrecognised. ${ }^{6}$

The comorbidity profile apart from ADHD is least studied; primarily because the DSM IV definition of dyslexia had excluded visual, hearing, intellectual and motor disabilities. Many neurological comorbidities are known to have SLD as association either due to disease or otherwise due to original insult. Epilepsy, autism, Attention deficit hyperactivity disorder (ADHD), cerebral palsy, genetic syndromes are few of the conditions in which SLD is likely to exist. The neurodevelopmental comorbidities appear to be overlooked.

This study aims to know the prevalence of these neuro developmental comorbidities in SLD; so that a comprehensive therapy plan can be targeted to cure.

\section{METHODS}

The study was aimed at understanding the prevalence of neurological and developmental comorbidities in mainstream school children being certified as SLD at our institute. Primary objective was to study the differential distribution of various comorbidities across SLD spectrum. Secondary objective was to check for prevalence of abnormal neurological examination findings including soft signs.

This study was conducted as a prospective observational study at a tertiary care pediatric institute.
Institutional Ethics Committee permission was taken prior to commencement of study.

Children from age 7-16 year referred from main stream schools with or without neurological disorders and had a SLD certification from our institute were included. Nonschooling children and children from special rehabilitatory schools were excluded. Children with major psychiatric disorders like depression, psychosis, behavioural disturbances and adjustment disorders were excluded.

Consecutive 100 certified cases of SLD from mainstream school certified by a team of pediatrician and psychologist were studied, after taking a written informed consent from parents and assent from children above age 7 years. It was a convenient sampling as only 119 cases were on record in the study year 2013 and 19 cases were excluded due to referral from pre-primary school or special school.

The diagnosis of SLD was confirmed as per DSM V, from available structured age appropriate psychological assessment by certifying team of specialists. Neurodevelopmental morbidities and clinical signs, symptoms were noted from notes of pediatrician. Information regarding Birth history, family history and medical history was based on recall by parents. ADHD diagnosis was confirmed as per DSM V criteria during parent interview. The data was analysed using Microsoft excel and the prevalence was studied as percentage with total number of study population as denominator.

\section{RESULTS}

In this study, out of 100 cases of SLD, $69 \%$ were boys and $31 \%$ were girls. Mean age of children was $12.2 \%$; median age of children was 13.5 years, although there were 3 children between ages 7-9 years (Table 1).

Table 1: Age distribution of SLD children from mainstream schools.

\begin{tabular}{|ll|}
\hline Age distribution & $\begin{array}{l}\text { Age wise distribution of SLD } \\
\text { cases on record }\end{array}$ \\
\hline 7 to $<9$ years & 3 \\
\hline 9 to $<11$ years & 22 \\
\hline 11 to $<13$ years & 20 \\
\hline 13 to $<15$ years & 33 \\
\hline 15 to $<16$ years & 22 \\
\hline \multicolumn{2}{|c|}{ Mean=12.2 year, Median 13.5 year } \\
\hline
\end{tabular}

Eighty three percent of children had impairment in all three domains of SLD; that is reading (dyslexia), writing (dysgraphia) and arithmetic (dyscalculia). Impairment of reading was seen in $94 \%$ cases; while impairment of writing was noted in $99 \%$ cases and impairment in calculations was seen in $86 \%$ cases of SLD as per DSM 
$\mathrm{V}$, as assessed by psychologist with age appropriate short tests for reading writing and calculations of previous standard.

As per Table 2, amongst total 100 cases, 39 children with SLD had no comorbidities. Amongst total 83 cases with all three domains of SLD affected, $46.98 \%$ cases (29) had no neuro developmental comorbidity.

Table 2: This study shows number boys and girls with SLD across different comorbidities.

\begin{tabular}{|lll|}
\hline \begin{tabular}{l} 
Sex distribution across comorbidities \\
\hline $\begin{array}{l}\text { Comorbidity } \\
\text { distribution } \\
\text { (total cases) }\end{array}$
\end{tabular} & Boys with SLD & Girls with SLD \\
\hline None (39) & 25 & 14 \\
\hline ADHD CT (38) & 30 & 8 \\
\hline $\begin{array}{l}\text { ADHD } \\
\text { Inattentive (15) }\end{array}$ & 8 & 7 \\
\hline Autism (3) & 1 & 2 \\
\hline Epilepsy(2) & 1 & 1 \\
\hline $\begin{array}{l}\text { Cerebral palsy } \\
(2)\end{array}$ & 1 & 1 \\
\hline NF1 (2) & 2 & 0 \\
\hline Erbs palsy (1) & 1 & 0 \\
\hline Feb seizures(8) & 7 & 1 \\
\hline Meningitis(3) & 2 & 1 \\
\hline
\end{tabular}

Commonest comorbidity noted was ADHD, in 53\% cases $(\mathrm{n}=100)$. Autism was noted in $3 \%$ cases (2 girls and 1 boy) while epilepsy and cerebral palsy were noted in $2 \%$ cases each. Three cases had history of meningitis and 8 cases had history of febrile seizures. Inattentive type ADHD was also an overlapping additional comorbidity in epilepsy, cerebral palsy and meningitis. Amongst 53 cases of SLD with ADHD, 56\% (30) cases were boys with ADHD of combined type, $15.09 \%$ (8) cases were boys of inattentive type ADHD while there were 8 girls with SLD and ADHD of combined type prevailing to $15.09 \%$.

There were two cases each of cerebral palsy and neurofibromatosis with all three domains affected.

Table 3 shows perinatal aetiological events across comorbidities. Twenty four percent children with SLD had significant prenatal history. In most cases it was fever and cough for three days, which included 14 cases of SLD with ADHD. Seven cases of SLD also had history of fever in second trimester antenatally.

Total $15 \%$ cases had required resuscitation at birth. These included 9 cases of ADHD, one each of epilepsy, cerebral palsy, febrile seizure, meningitis and two cases with neurofibromatosis.

Of the 39 cases of SLD without co-morbidities $18.4 \%$ had significant antenatal history and $7.6 \%$ had neonatal hospitalization.

Table 3: Antenatal and prerinatal probable factors across comorbidities.

\begin{tabular}{|c|c|c|c|c|c|c|c|c|c|}
\hline $\begin{array}{l}\text { SLD } \\
\text { comorbidities } \\
\text { (cases) }\end{array}$ & $\begin{array}{l}\text { Antenatal } \\
\text { risk } \\
\text { present }\end{array}$ & $\begin{array}{l}\text { Antenatal } \\
\text { no risk }\end{array}$ & $\begin{array}{l}\text { Birth } \\
\text { resuscitation } \\
\text { needed }\end{array}$ & $\begin{array}{l}\text { Birth } \\
\text { resuscitation } \\
\text { not needed }\end{array}$ & $\begin{array}{l}\text { Term } \\
\text { baby }\end{array}$ & $\begin{array}{l}\text { Preterm } \\
\text { baby }\end{array}$ & $\begin{array}{l}\text { NICU } \\
\text { stay } \\
\text { yes } \\
<7 \text { days }\end{array}$ & $\begin{array}{l}\text { NICU } \\
\text { stay } \\
\text { yes } \\
>7 \text { d }\end{array}$ & $\begin{array}{l}\text { No } \\
\text { NICU } \\
\text { stay }\end{array}$ \\
\hline $\begin{array}{l}\text { ADHD CT } \\
(38)\end{array}$ & 8 & 30 & 8 & 30 & 31 & 7 & 2 & 4 & 30 \\
\hline ADHD I (15) & 5 & 9 & 1 & 13 & 13 & 1 & 2 & 1 & 11 \\
\hline Autism (3) & 1 & 2 & 0 & 3 & 3 & 0 & & & 3 \\
\hline Epilepsy (2) & 0 & 2 & 1 & 1 & 2 & 0 & 0 & 1 & 1 \\
\hline $\begin{array}{l}\text { Cerebral palsy } \\
\text { (2) }\end{array}$ & 1 & 1 & 1 & 1 & 2 & 0 & 1 & 1 & 0 \\
\hline NF1(2) & 0 & 2 & 0 & 2 & 2 & 0 & 0 & 0 & 2 \\
\hline Erbs palsy (1) & 0 & 1 & 1 & 0 & 1 & 0 & 1 & 0 & 0 \\
\hline $\begin{array}{l}\text { Feb seizures } \\
\text { (8) }\end{array}$ & 1 & 7 & 2 & 6 & 7 & 1 & 1 & 1 & 6 \\
\hline Meningitis (3) & 1 & 2 & 1 & 2 & 2 & 1 & 0 & 2 & 1 \\
\hline $\begin{array}{l}\text { NO } \\
\text { comorbidity } \\
(39)\end{array}$ & 7 & 31 & 1 & 38 & 36 & 2 & 1 & 2 & 35 \\
\hline
\end{tabular}


Parents of $31.5 \%$ cases with SLD with ADHD-combined type had recalled a positive family history in father in the form of early year learning difficulties. Also parents of $20 \%$ of SLD with inattention type had paternal history of inattention in their primary school age.

Amongst two kids who had SLD with Neurofibromatosis; there was a family history of neurofibromatosis but not of SLD.

Only three cases had microcephaly, two cerebral palsy cases and third one with history of meningitis.

Fine motor and language milestones were delayed in SLD with epilepsy, cerebral palsy, and history of meningitis. Language milestones were delayed in all 3 cases of autism and 8 cases of ADHD. Fine motor milestones were delayed in $49 \%$ of SLD with ADHD.
Nocturnal Enuresis was noted in 10 cases out of 53 who had SLD with ADHD.

More so, the higher functions like speech, gait, left-right orientation, visual spatial skills and ability to tell time were affected significantly in those SLD with ADHD (Table 4), but also in few SLD children without any comorbidity. Despite being main stream, $18 \%$ of ADHD CT type had speech delay, $9.4 \%$ had gait issues, and $62.2 \%$ had poor directionality. Among the three students with autism, all had abnormal speech and 2 had poor directionality and visual spatial skills. Amongst 39 children with no comorbidities, $12.5 \%$ had abnormal gait, $25 \%$ had speech deficit and $37.5 \%$ had poor time orientation and $50 \%$ had poor directionality. Seventy five percent of SLD children without added comorbidities had poor visual spatial skills.

Table 4: Abnormal higher neurological functions in SLD children with comorbidities.

\begin{tabular}{|llllll|}
\hline SLD Comorbidities (cases) & Speech & Gait & L-R orientation & Time orientation & Visuospatial skills \\
\hline ADHD C (38) & 10 & 4 & 24 & 17 & 31 \\
\hline ADHD I (15) & 0 & 1 & 9 & 7 & 10 \\
\hline Autism (3) & 3 & 0 & 2 & 1 & 2 \\
\hline Epilepsy (2) & 1 & 0 & 2 & 2 & 2 \\
\hline Cerebral palsy (2) & 2 & 1 & 2 & 1 & 1 \\
\hline NF1(2) & 0 & 0 & 1 & 1 & 1 \\
\hline Erbs palsy (1) & 0 & 0 & 0 & 0 & 1 \\
\hline Feb seizures (8) & 2 & 1 & 4 & 3 & 6 \\
\hline Meningitis (3) & 0 & 1 & 3 & 3 & 3 \\
\hline NO cormorbidity (39) & 4 & 0 & 6 & 6 & 11 \\
\hline
\end{tabular}

Table 5: Abnormal gross and soft neurological signs in SLD children.

\begin{tabular}{|lllllll|}
\hline Comorbidity & Tone & Power & DTR & Plantar & Cerebellar signs & Soft CNS signs \\
\hline ADHD CT (38) & 16 & 0 & 4 & 3 & 1 & 24 \\
\hline ADHD I (15) & 3 & 0 & 0 & 0 & 0 & 7 \\
\hline Autism (3) & 0 & 0 & 0 & 0 & 0 & 3 \\
\hline Epilepsy (2) & 0 & 0 & 0 & 0 & 0 & 2 \\
\hline Cerebral palsy (2) & 2 & 1 & 2 & 2 & 0 & 2 \\
\hline NF1(2) & 0 & 0 & 0 & 0 & 0 & 1 \\
\hline Erb's palsy (1) & 1 & 1 & 1 & 0 & 0 & 6 \\
\hline Feb seizures (8) & 3 & 0 & 2 & 2 & 0 & 3 \\
\hline Meningitis (3) & 3 & 0 & 1 & 1 & 1 & 13 \\
\hline NO comorbidity (39) & 3 & 0 & 0 & 0 & 1 & 1 \\
\hline
\end{tabular}

Gross CNS examination abnormalities were very infrequent. In SLD with ADHD of combined type, 38.5\% had tone issues as compared to $20 \%$ amongst inattention type. Ten percent children had abnormal deep tendon reflexes while extensor plantar and cerebellar signs were seen in $7.8 \%$ and $2.6 \%$ children respectively. Minor tone issues were noted in children who had obvious history or CNS insult in the form of meningitis or cerebral palsy (Table 5).
In cases of SLD without any comorbidity, $7.6 \%$ children had minor tone abnormalities and $2.5 \%$ of these had cerebellar signs.

A high percentage of children with SLD had soft neurological signs. Astereognosis was seen in $23 \%$ cases, graphesthesia was affected in $28 \%$ cases while dysdiadochokinesia was present in $31 \%$ cases. Soft neurological signs were present in $58.4 \%$ of SLD with ADHD. All children with some or other neurological 
morbidity had at least one soft neurological sign. Amongst SLD without added comorbidities, 33.3\% (13) had soft neurological signs (Table 5).

Asterognosis, dysdiadochokinesia, abnormal graphesthesia, tandem walking, finger nose test abnormalities and abnormal two point discrimination were seen more in boys compared to girls. Sensory extinction and dysdiadochokinesia coordination abnormalities were by far the commonest soft neurological sign amongst boys and girls with SLD (Figure 1).

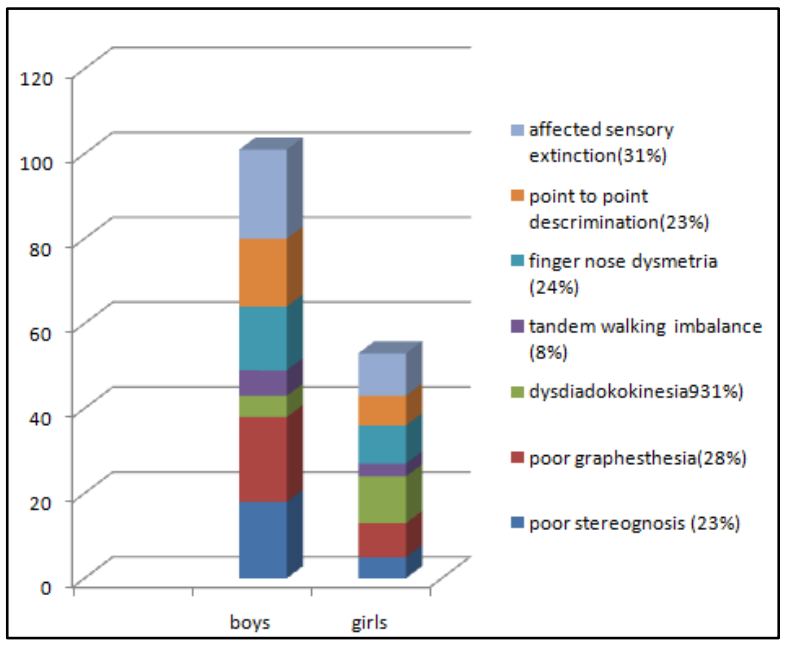

Figure 1: Sex distribution of various soft neurological signs amongst SpLD.

\section{DISCUSSION}

Individual conditions and their association with learning disabilities have been studied in great details but the spectrum of comorbidities that are associated with LD aren't really explored.

The male:female sex ratio was $2.2: 1,69 \%$ SLD children were boys. A study in Taiwan had male:female ratio of 5.8:1. ${ }^{7}$ Our study correlated well with Indian study in 2004, with sex ratio of $2.3: 1 .^{8}$ In a study from Bikaner, the sex ratio was $11.4 \%$ vs $7.4 \%{ }^{9}$

In previous studies, median age of presentation was 11.4 years while our study had median age of 14 years, with youngest being 7 year old. ${ }^{8}$ Al-mamari et al found Mean age of children with learning disorders in Omani children was 8.5 years. ${ }^{10} \mathrm{~A}$ higher median age at diagnosis points to delayed referral.

Most common impairment in this study was in writing domain (dysgraphia), seen in 99\% cases, impaired reading(dyslexia) was in $94 \%$ cases while $86 \%$ cases had issues in arithmetic. ${ }^{8}$ Globally the prevalence is near about same with writing impairment in $96 \%$ of learning disability children, with dyscalculia in $74 \%$ cases. Reading disability was noted in $60 \%$ cases. Landerl K et al in a large population based study $(\mathrm{N}=2586)$ noted that comorbidity rates of impairment in these domains were 45 times higher in those having at least one domain affection, compared to normal population. Accordingly, we had $83 \%$ SLD children with affection of all 3 domains. ${ }^{11}$

As per literature, ADHD is known to coexist as commonest comorbidity, accounting for $12-24 \%$ cases of SLD. ${ }^{12}$ In our study, it was $53 \%$. Margari et al in a recent study reported ADHD as $33 \%$ comorbidity in SLD. ${ }^{13}$ Mayes et al in 2000, reported SLD in 20\% of ADHD cases in a population of 119 children from age 8-16 years. ${ }^{14} \mathrm{~A}$ higher mean comorbidity was reported as $45.1 \%$ in a review of 17 studies from 2001-2011 by Dupaul GJ et al. ${ }^{15}$ This data must be viewed as tentative because of wide variations and difficulties defining ADHD. The imbalanced nature of relationship suggests that these two are likely to be independent syndromes.

Sex predisposition was striking with ADHD as co morbidity in this study, having $55.07 \%(n=69)$ boys with SLD and ADHD; 43\% (30) were of ADHD combined type. Amongst the girls (n-31\%), 48\% (15) had ADHD as co morbidity, with $25 \%$ of ADHD combined type. Even this association is not yet described in literature in children with SLD. In general ADHD is more comorbid in boys. LD and ADHD are considered by many as a continuum, interrelated and are usual association. Yoshimasu K, Barbaresi WJ followed 5718 children and found the cumulative incidence of SLD higher in children with ADHD, than otherwise. ${ }^{16}$ The higher prevalence of ADHD in our study does confirm the same and point towards a common etiology and therapy.

Although 39 cases had significant antenatal or perinatal history, more so in cases with ADHD as added morbidity, the previous studies reported significant perinatal history in $30 \%$ of subjects. ${ }^{8}$

Positive family history suggestive of LD was noted in $31.5 \%$ of combined type ADHD and $20 \%$ of inattentive type. In all other comorbidities no family history was noted except in case of neurofibromatosis. There is no documentation available in literature with respect to same.

In our study, 5\% had delayed gross motor milestones, $35 \%$ had delayed fine motor milestones. Language was delayed in $43 \%$ cases.

Significantly abnormal antenatal history was $21 \%$ ADHD of combined type, which was more $(33.3 \%)$ than ADHD inattentive type. No past studies were available to compare this.

In this study, 5\% children had delayed gross motor milestones and $35 \%$ cases had delayed fine motor milestones. In past literature, delayed milestones were recorded in less than one third of cases. ${ }^{8}$ This difference 
may be attributed to memory bias of parents. Of the 39 children without comorbidities, $17.9 \%$ had fine motor delay and $35.8 \%$ had gross motor delay. In this study, $10 \%$ cases with SLD and ADHD as comorbidity had delayed gross motor milestones and 50\% had delayed fine motor milestones. There are separate studies on milestone delay in LD or ADHD, but there is no data on delay in LD with ADHD. ${ }^{17,18}$

Language milestone was delayed in $43 \%$ children and $22 \%$ had history of nocturnal enuresis.

Amongst 39 SLD children without comorbidities $35.8 \%$ had language delay and $17.9 \%$ had fine motor delay. No similar studies were on record.

These things point out towards possible complex multiple neurodeficits independently or together resulting in SLD.

Soft neurological signs were present in $58.4 \%$ of children with ADHD and $33.33 \%$ of kids without comorbidities. Various soft neurological signs were noted by Karande et al in $54 \%$ cases with LD. ${ }^{8}$ Some studies noted unusually high prevalence of soft neurological signs in LD. In literature, no data was available with soft signs in presence of comorbidities.

Approximately a third to a fourth of patients with epilepsies have learning disability and conversely $6-24 \%$ of SLD may have seizure disorders. ${ }^{19}$

In our study, only $2 \%$ had idiopathic epilepsy. Both these children were well controlled on valproate therapy. Dyslexia was a known morbidity in $19.4 \%$ of children with rolandic epilepsy in a recent study by Oliveria et al. $^{20}$

Discrepancy between these and our results are likely to be due to small sample size and children from higher middle class main stream school. SLD severity is expected to be more with early age of onset of seizures. As the sample size was from mainstream and involved elder kids; cases of epilepsy with SLD with IQ deficits automatically got dropped. This may explain low incidence of seizure cases in our study. Our study, had 8 children with history of febrile seizures in past. Of these five were typical and three were atypical. These findings confirm of no specific association of febrile seizure history with SLD as concluded by Norgaard $\mathrm{M}$ et al. ${ }^{21}$

Association between CP, epilepsy and SLD is known throughout literature. We had only $2 \%$ cases of CP in this study. As the mean age was 12.5 years, it would have been unlikely for a cognitively abnormal child to study in main stream.

Similarly apart from motor deficit causing writing difficulty, we could not find any reason for the SLD in the case of Erb's palsy.
There are no studies with concurrence of autism and LD; we had three children with same. While special education is required for both; more evidence is needed to understand their association. In this study, 2 out of three autism children with SLD were girls. Autism is known to be severe in girls but SLD concurrence with autism isn't studied yet.

Cognitive impairment is a known long term sequel of bacterial and viral meningitis or encephalitis. There were three cases with past history of CNS infection. The association is not studied in literature.

Structural brain imaging in LD was reported as showing loss of grey mater volume and loss of asymmetry of left planum temporal. In this study neuroimaging was available only in few symptomatic cases, of cerebral palsy, meningitis and epilepsy. The findings were correlating with primary insult in some while in others it was normal.

This study was limited by many factors despite good sample size. The children were from main stream schools that had bias making samples size population without intellectual disability. Most children were above age 10 years, making age appropriate assessment tricky. Children were enrolled after SLD certification, so those who had been referred but were not certified could not be studied. Also despite some good references we could not directly compare our results to them as all references had cases defined as per DSM IV as dyslexia and this study had the latest broad spectrum definition while applying same. This study had excluded psychiatric morbidities for technical reasons.

\section{CONCLUSION}

ADHD of combined type was most common morbidity with SLD in children from main stream school. A good number of these cases had abnormal antenatal or prenatal history and soft neurological signs. Autism, Epilepsy and CP were additional comorbidities that could not be neglected. Soft neurological signs were likely to be abnormal in LD with or without ADHD.

Fine motor and language delay was frequently associated with LD. This study suggests the possibility of complex multiple neurodeficits independently or together resulting in SLD.

A large multicentric study is needed to look for soft neurological signs, neuroimaging and organic causes of SLD, so as to help in therapy.

\section{ACKNOWLEDGEMENTS}

We thank Dean TNMC Mumbai for permission of publication of this research paper. 
Funding: No funding sources

Conflict of interest: None declared

Ethical approval: Ethical Approval from Institutional ethics committee

\section{REFERENCES}

1. Kulkarni M, Kalantre S, Upadhye S, Karande S, Ahuja S. Approach to learning disability. Indian J Pediatr. 2001;68(6):539-46.

2. Specific learning disorder. Available at: http://www.dsm5.org/Documents/Specific Learning Disorder Fact Sheet. Accessed March 8, 2016.

3. Alves LM, Siqueira CM, Ferreira Mdo C, Alves JF, Lodi DF, Bicalho L et al. Rapid naming in Brazilian students with dyslexia and attention deficit hyperactivity disorder. Front Psychol. 2016;7:21.

4. Schulte-körne G. [Specific learning disabilities from DSM-IV to DSM-5]. Z Kinder Jugendpsychiatr Psychother. 2014;42(5):369-72.

5. Pham AV, Riviere A. Specific learning disorders and ADHD: current issues in diagnosis across clinical and educational settings. Curr Psychiatry Rep. 2015;17(6):38.

6. Sahoo MK, Biswas H, Padhy SK. Psychological comorbidity in children with specific learning disorders. J Family Med Prim Care. 2015;4(1):21-5.

7. Huang YF, Chang HL, Wu YY, Huang YS, Liang HY. Clinical characteristics of children with learning disorders in Taiwan. Chang Gung Med J. 2007;30(5):423-9.

8. Karande S, Satam N, Kulkarni M, Sholapurwala R, Chitre A, Shah N. Clinical and psycho educational profile of children with specific learning disability and co-occurring attention-deficit hyperactivity disorder. Indian J Med Sci. 2007;61(12):639-47.

9. Choudhary M, Jain A, Chahar C, Singhal AK. A case control study on specific learning disorders in school going children in Bikaner city. Indian $\mathbf{J}$ Pediatr. 2012;79(11):1477-81.

10. Al-mamari WS, Emam MM, Al-futaisi AM, Kazem AM. Comorbidity of learning disorders and attention deficit hyperactivity disorder in a sample of Omani school children. Sultan Qaboos Univ Med J. 2015;15(4):e528-33.
11. Landerl K, Moll K. Comorbidity of learning disorders: prevalence and familial transmission. J Child Psychol Psychiatry. 2010;51(3):287-94.

12. Karande S, Kulkarni M. Specific learning disability: the invisible handicap. Indian Pediatr. 2005;42(4):315-9.

13. Margari L, Buttiglione M, Craig F, Cristella A, de Giambattista C, Matera E et al. Neuropsychopathological comorbidities in learning disorders. BMC Neurol. 2013;13:198.

14. Mayes SD, Calhoun SL, Crowell EW. Learning disabilities and ADHD: overlapping spectrumn disorders. J Learn Disabil. 2000;33(5):417-24.

15. Dupaul GJ, Gormley MJ, Laracy SD. Comorbidity of LD and ADHD: implications of DSM-5 for assessment and treatment. J Learn Disabil. 2013;46(1):43-51.

16. Yoshimasu K, Barbaresi WJ, Colligan RC, Killian JM, Voigt RG, Weaver AL et al. Written-language disorder among children with and without ADHD in a population-based birth cohort. Pediatrics. 2011;128(3):e605-12.

17. O'byrne JJ, Lynch SA, Treacy EP, King MD, Betts DR, Mayne PD et al. Unexplained developmental delay/learning disability: guidelines for best practice protocol for first line assessment and genetic/metabolic/radiological investigations. Ir J Med Sci. 2016;185(1):241-8.

18. Shapiro BK, Palmer FB, Antell S, Bilker S, Ross A, Capute AJ. Precursors of reading delay: neurodevelopmental milestones. Pediatrics. 1990;85:416-20.

19. Lhatoo SD, Sander JW. The epidemiology of epilepsy and learning disability. Epilepsia. 2001;42(1):6-9.

20. Oliveira EP, Neri ML, Capelatto LL, Guimarães CA, Guerreiro MM. Rolandic epilepsy and dyslexia. Arq Neuropsiquiatr. 2014;72(11):826-31.

21. Nørgaard M, Ehrenstein V, Mahon BE, Nielsen GL, Rothman KJ, Sørensen HT. Febrile seizures and cognitive function in young adult life: a prevalence study in Danish conscripts. J Pediatr. 2009;155(3):404-9.

Cite this article as: Somale A, Kondekar SV, Rathi S, Iyer N. Neurodevelopmental comorbidity profile in specific learning disorders. Int J Contemp Pediatr 2016:3:355-61. 